\title{
Nasal Cavity Non-Hodgkin Lymphoma
}

National Cancer Institute

\section{Source}

National Cancer Institute. Nasal Cavity Non-Hodgkin Lymphoma. NCI Thesaurus. Code C6075.

A primary non-Hodgkin lymphoma that affects the nasal cavity and the bulk of the tumor is in this anatomic area. The majority of the cases are nasal type extranodal NK/T-cell lymphomas and diffuse large B-cell lymphomas. 